See discussions, stats, and author profiles for this publication at: https://www.researchgate.net/publication/334946345

\title{
Life Cycle Cost Management of Concrete Structures
}

Conference Paper · August 2019

CITATIONS

0

10 authors, including:

- Jose Campos Matos

University of Minho

165 PUBLICATIONS 355 CITATIONS

SEE PROFILE

Poul Linneberg

COWI

12 PUBLICATIONS 12 CITATIONS

SEE PROFILE

Some of the authors of this publication are also working on these related projects:

Project Fracture Mechanics in Structural Engineering View project

Project 16th edition of the International Probabilistic Workshop (IPW2018), View project
READS

201

13. Anders Ole Stubbe Solgaard

18 PUBlications 150 CITATIONS

SEE PROFILE

Alfred Strauss

University of Natural Resources and Life Sciences Vienna 286 PUBLICATIONS 1,656 CITATIONS

SEE PROFILE 


\title{
Life Cycle Cost Management of Concrete Structures
}

\author{
José Matos
}

Department of Civil Engineering, Engineering School, University of Minho, Campus de Azurém, 4800-058, Guimarães, Portugal

Anders Solgaard, Poul Linneberg

COWI A/S, Parallelvej 2, DK-2800 Kongens, Lyngby, Denmark

\section{Mauricio Sanchez Silva}

3 Department of Civil \& Environmental Engineering, Geomaterials and Infrastructure Systems Group, Universidad de Los Andes, Carrera 1 Este N. 19A-40 Edificio Mario Laserna, Off. ML630, Bogotá, Colombia

\section{Alfred Strauss}

Institute of Structural Engineering (IKI), BOKU, Peter-Jordan-Straße 821190 Vienna, Austria

Irina Stipanovic

University of Twente, Faculty of Engineering Technology, Drienerlolaan 5, 7522NB Enschede, Netherlands; Infra Plan Consulting, Luke Kaliterne 7, Zagreb, Croatia

\section{Joan Casas}

Department of Civil and Environmental Engineering, Technical University of CataloniaBarcelonaTech, JordiGirona 1-3 Campus Nord, Modul C1 08034, Barcelona, Spain

\section{Snezana Masovic}

Universityof Belgrade, Faculty of Civil Engineering, Bulevarkralja Aleksandra 73, Beograd, Serbia

\section{Colin Caprani}

Department of Civil Engineering, Monash University, 23 College Walk (Bld 60), Clayton Campus, Melbourne, Australia

\section{Drahomir Novak}

Structural Mechanics Faculty of Civil Engineering Brno University of Technology Veveri 95, 66237 Brno, Czech Republic

\section{Mitsuyoshi Akiyama}

Department of Civil and Environmental Engineering, Waseda University - 3-4-1, Okubo, Shinjuku, 169-8555 Tokyo, Japan

Contact: jmatos@civil.uminho.pt

\section{Abstract}

Tools, guidelines and standards for assessment of Life Cycle Cost (LCC) of built environment e.g. buildings, infrastructure assets etc. have gained impact over the past years. Owner and operator application of tools, guidelines and standards enhances optimization of operation and maintenance with due respect to their budgets. In order to aid owners, operators and their designers, a task group under fib has been established to prepare a state-of-the-art report regarding LCC analyses of concrete assets. The state-of-the-art report contains a description of existing LCC standards and guidelines, their applicability, the definition of different cost elements, 
and the treatment of uncertain information in a reliability or risk based framework, etc. providing the reader with background information and methodology for preparation of such analysis. Moreover, the report contains case studies, presenting the applicability of the LCC analysis methodology.

Keywords: Life Cycle Cost (LCC), Concrete Structures, Framework.

\section{Introduction}

The fib Task Group 8.4 concerning LCC tools for concrete infrastructures, has the aim of presenting the LCC framework and some applications in concrete structures. A fib bulletin, state of art technical report on LCC applications to concrete structures, will be the main deliverable of this Task Group. The bulletin structure is: Chapter 1. Introduction and General Background; Chapter 2. Existing LCC standards, guidelines and research projects; Chapter 3. Methodology of LCC analysis; Chapter 4. Cost elements in LCC models; Chapter 5. Uncertainties, reliability and risk; Chapter 6. Case studies.

The aim of this paper is to present an overview of the on-going works for the bulletin preparation with short descriptions of each of the chapters of the bulletin.

\section{Added value of LCC}

Within built environment projects (bridges, buildings, highways, ports, airports, etc.), one or few actors carry the burden of not only the initial investment but also of the maintenance and operation, which draw attention to the decisions throughout the projects lifetime. Thus, in order to improve the long-term decision making it is important to shift the focus of funding towards system preservation and look at both up-front and long-term costs to ensure sustainability of future budgets and better management of structures. Within this context, the life cycle cost analysis (LCCA) plays a significant role in modern engineering project management.

Traditionally, construction project procurement was undertaken without further consideration as to the costs, which would be incurred from construction to disposal; this approach focused mainly on finding the cheapest technically feasible alternative. On the contrary, modern engineering focuses on the balance between value and risk of quality and price. Within the management of the built environment, owners have an obligation to ensure that the structure is maintained at an acceptable standard throughout its lifetime. As these structures are long-term assets, not having an integrated and long-term plan for regular operation may considerably affect the returns on investment [1].

The aspects where LCC analysis has its major impact over traditional design are classified as follows:

1. System operation and project development: it allows involving activities as operation policies (inspection, interventions, monitoring, etc.); economic exploitation (improvement service, charge strategy, financial strategies, etc.) and future developments (expansion, technology update, etc.)

2. Cost structure of projects: It provides a decision making framework that allows to assess the overall costs of a project to select the design and management requirements [2]

3. Sustainability implications: Pollution control, rational use of resources and financial feasibility of engineering projects.

The built environment consist of changing entities for which predictions are uncertain, i.e. there is a need for updating decision strategies. Thus, LCC analysis can be implemented in different aspects such as:

1. Help to select the best alternative to meet a project objective;

2. Evaluate a design requirement within a specified project;

3. Compare overall costs between different types of projects; 
4. Calculate the most cost-effective approaches to project implementation (provides an inservice budget);

5. Evaluate the most attractive bid proposal;

6. Compare costs between different maintenance and operation strategies;

7. Calculate the most cost-effective approaches to maintenance and operation (incl. optimization).

The advantages regarding the use of LCC analysis for both new and existing structures are as follows:

1. Encourages businesses to find a correct balance between investment costs and operating expenses;

2. Enables investment options to be more effectively evaluated;

3. Considers the impact of all costs rather than only initial capital costs;

4. Facilitates choice between competing alternatives;

5. May consider environmental impact and sustainability of construction.

It should be noted that the tools and resources for conducting and performing LCC analysis exist, and what is needed to expand their adoption are incentives, legislations and introducing performance evaluation into the planning process.

\section{Existing LCC standards and guidelines}

LCC analyses are typically considered in parallel with other analyses related to safety, service (e.g. availability), sustainability (incl. Life Cycle Assessment) etc. Fully integration of these analyses calls for multi-criteria analyses because of difficulties in monetization of all impacts.

LCC analyses are typically based on net present values, where a discount rate is used to convert cash flows occurring at different time to a common time, to reflect the time value of money. The discount rate has a significant impact on the final result of LCC analyses and hence the selection of a suitable discount rate is crucial for the decision-making, see e.g. [3] and [4].
Regarding LCC standards, some are purely generic (e.g. [6]) while others are (semi) asset specific (e.g. [7], [3], and [8]). A vast amount of guidelines and handbooks, also dealing with LCC, has been published. Especially, fib Bulletin 71 [9] on integrated life cycle assessment of concrete structures, is a relevant report covering several issues related to LCC. Some guidelines are asset specific such as [10], [11], and [12], relevant for infrastructure assets, while others are generic, e.g. [13].

A number of software packages exist for LCC analyses - some are tailor made for a specific asset, others are generic. An application of some LCC analysis software can be found in MAINLINE [14], dealing with infrastructure assets.

The engineering community within concrete structures moves toward performance-based design and management. Both topics require treatment of uncertainties, which motivates adoption of risk and reliability based approaches. In particular for time-dependent deterioration of concrete structures, the review of existing LCC standards and guidelines has shown that there appears to be a general lack of guidance/models for time-dependent deterioration of concrete structures in LCC models. Hence, guidance and models for consideration of time-dependent deterioration of concrete structures is required to improve the applicability of LCC analyses for concrete structures. Reference for further information is made to the state-of-the-art collection on risk-based lifecycle performance of structural systems compiled in Journal of Structural Engineering, vol. 142 (9), 2016 [15].

\section{$4 \quad$ LCC analysis methodology}

Considering the aim and scope of LCC analyses financial factors (e.g. cost of future investments, discount rates, etc.), inter-generational responsibility, environmental aspects and sustainability, among others, become relevant elements in the analysis and the definition of the project characteristics. There are three forces driving the evolution and use of LCC during the last decade: (1) government regulations all over the world are moving in the direction of life cycle "accountability"; (2) businesses of all sorts have 
recognized that LCC is the key to fostering efficiency and continuous improvement; and (3) continuous and long-term environmental protection has emerged as a criterion in both consumer markets and government procurement guidelines.

Different methodologies can be observed for the calculation of LCC. In this sense, Davis Langdon carried out during 2006-2007 an analysis and evaluation of the different national approaches to LCC and developed an EU-wide methodological framework for the estimation of life cycle costs for buildings and constructed assets [1]. As part of the work, they elaborated guidance on how to make cost estimates at each stage of a construction project, from the initial appraisal to the completion and post-occupation phases, including the disposal of the asset. A number of specific case studies were undertaken to illustrate the practical implementation of this EU-wide approach. One conclusion of this study is that the variety of uses of LCC in practice means that it is very difficult to specify a single approach and therefore no single, prescriptive approach to LCC in the current European marketplace is feasible.

The study recognizes that a common methodology needs to be applicable not only to different periods of time over the life cycle of a constructed asset, but also at various points in the life of the asset. Users may adopt an approach to LCC at the inception stage, at the design stage, at the stage of bidding for a construction contract, at the commencement of construction, at the beginning of an O\&M service contract, at the beginning of a warranty period, etc.

In practice LCC is used for a wide range of analysis periods, and the corresponding methodology for LCC analysis needs to accommodate such variety which may include the life cycle (cradle to grave) from inception to disposal of a construction asset, and may also include the period of a long-term service contract (e.g. 25-30 years), or a predetermined period relating to the client's/user's interest in the constructed asset under consideration. This could include periods covering design, construction and short-term operation, for example, or be restricted to periods that include only the maintenance and replacement (adaptation) of major components. It could also cover the period of Facilities Management (FM) or Public Private Partnership (PPP) contracts.

The following steps can be identified as general in any method of LCC analysis: (1) definition of the project objective and scope; (2) definition of minimum performance requirements and restrictions; (3) identification of alternative options; (3) establishment of analysis assumptions and parameters; (4) building a LCC model; (5) building a cost and time data base; and (6) performing a LCC evaluation.

\section{Cost categories in LCC models}

Economic parameters related to the construction, maintenance and end-of-life phase of an object for the LCC analysis are quite well recorded and quantification methods are developed. However, a lot of unknowns and discussions are still ongoing regarding societal and environmental parameters for such analyses.

Three cost categories are suggested that may be used to build LCC models in order to assist decision-makers at all levels and within all phases in selecting the most cost-effective alternative from an array of applicable alternatives, namely agency costs, user costs and society costs. Agency costs represent direct costs incurred during the asset life cycle, and user and society costs are indirect costs which occurred due to the usage of the asset.

Agency costs are usually divided into three subcategories, namely design and construction costs, maintenance costs and end of life costs. The total discounted agency costs are the sum of those three sub cost categories.

The construction costs are those costs that the agency must cover in order to build an asset. These construction costs are related to the acquisition of a new asset that for instance, belongs to a new construction plan or to a service demand. This cost can also be related to the replacement of an asset that has already reached the end of its service life. The construction costs include labour cost, material cost, equipment costs and indirect costs. Indirect costs are those 
costs that are not directly accounted to an object, and may include personnel, administration and security costs.

The user costs are the costs that are born directly by the user of the structure (e.g. bridge, building, infrastructure, etc.).These costs can be divided into several sub-categories of which the most common and most significant are taken into account in this study, namely: user operating costs, operational delay costs, and crash costs or accident costs. These costs are all result of the work zones that are associated with the construction and maintenance activities performed at the object during its life cycle. It is therefore essential for the determination of these costs that the amount of maintenance (frequency and duration) that is needed and the impact of these maintenance activities on the operation and safety are estimated carefully. The maintenance scenario that is used for the determination of the maintenance costs should therefore include the information about the effect of the maintenance activity on the operation (i.e. in the case of bridge total traffic delay calculated based on the extra travel time per vehicle and the duration of the activity) and the effect on the safety (i.e. the number of extra accidents due to the maintenance activity).

Society costs are costs borne by society at large, as for example the impact on the environment. Environmental costs are the costs that are caused by use of energy and resources during the construction, maintenance and end-of-life phase of the bridge and the accompanying emissions to the environment. There are a couple of general steps associated with environmental impact or life cycle assessment (LCA) studies. According to [17], an international guideline on how to perform an LCA, there are four steps in the life cycle framework: Goal and scope definition, Inventory analysis, Impact assessment and Interpretation.

Additionally some of the structures, such as bridges or special buildings might be seen as monuments and icons which the citizens may relate with the cultural heritage of a certain area. This atmosphere and the will to identify certain area and its values with an icon may motivate for bold and spectacular solutions. Some alternatives have exceeded all cost estimates but they have been chosen as aesthetically the best. Certainly, there is a hidden value behind the external shape of structures, such as bridges in some special locations. The inclusion of this value in the evaluation process leads to eliminating the worst aspects of bridge design and encourages the best. This value should be computed for the different feasible proposals in fair-bases and converted to a measurable value to be able to include it in the LCC model.

\section{Uncertainties, reliability and risk}

Performing the actual calculations of LCC involves a number of uncertain parameters (e.g. service life, values of discount rates, inspection costs, maintenance costs, evolution of loads including natural disasters, probability of failure, rehabilitation costs, etc.). Accordingly, it is known that both intrinsic (aleatory) and modelling (epistemic) uncertainties affect LCC. Failure cost uncertainty, as well as more general cost uncertainty, should be factored into the general structural risk and reliability problem. Throughout the lifetime of a concrete structure, there is an inherent risk in its failure (according to some limit state), alongside which there are the costs of such failures, should they occur. Generally, it is considered that a financial risk is the probability of a failure event times the cost of its consequences. Obviously then, this risk cost should be factored into the consideration of LCC, since it can be a significant component affecting decision making regarding management of the asset (e.g. for the avoidance of costly failures). Further, as the structure ages, this balance of risk and reliability alters (time-dependent effects), and this must also be considered in achieving an overall LCC estimate. The most complex risk assessment involves time-dependent reliability analysis of various limit states and time-dependent modelling of losses (presented in monetary units - i.e. "costs") related to the spectrum of consequences. With these factors in mind, the background for assessing reliability and risk, as they should contribute to an LCC are identified.

The uncertainties are generally classified as resistance variables (e.g. concrete strength), 
regular-usage load variables (e.g. traffic loads), hazards (e.g. earthquake), and cost variables (e.g. labour), see Table 1. A background on the appropriate statistical modelling of many forms of these variables will be provided in the bulletin. Methods of combining simultaneously acting loads will be explained. 
Table 1. Aleatoric parameters

\begin{tabular}{|c|c|c|c|}
\hline Resistance & Loads & Hazards & Cost Elements \\
\hline $\begin{array}{l}\text { Concrete } \\
\text { strength } \\
\text { Geometry } \\
\text { Reinforce- } \\
\text { ment } \\
\text { Pre-stress } \\
\text { strands } \\
\text { Creep and } \\
\text { shrinkage } \\
\text { Corrosion }\end{array}$ & $\begin{array}{l}\text { Self-weight } \\
\text { Building live } \\
\text { loads } \\
\text { Highway } \\
\text { traffic } \\
\text { Railway } \\
\text { Pedestrian } \\
\text { loads } \\
\text { Wind loads } \\
\text { Snow } \\
\text { Earth } \\
\text { pressures } \\
\end{array}$ & $\begin{array}{l}\text { Earthquake } \\
\text { Blast } \\
\text { Impact } \\
\text { Fire } \\
\text { Tsunami } \\
\text { Overload }\end{array}$ & $\begin{array}{c}\text { Construction } \\
\text { Inspection } \\
\text { Maintenance } \\
\text { Repairs } \\
\text { Human } \\
\text { loss/injury } \\
\text { Property } \\
\text { damage } \\
\text { Disruption } \\
\text { Environmental } \\
\text { Social/political }\end{array}$ \\
\hline
\end{tabular}

Having summarized the modelling and the uncertain variables in an LCC, an overview of the basic principles of risk management in civil engineering is presented based on [16] and [18]. Combination of decision theory and risk assessment enables consideration of alternatives to reduce risk. Risk mitigation measures, aimed to reduce the probabilities of a scenario and/or probabilities of losses, incur costs. Optimization should be supported by data concerning measures efficiency and related costs. Some of the riskbased approaches that are suitable to address the problem are described, and inform readers on how to input/leverage existing tools to accommodate the models pretended. Essentially, it terminates with an explanation for the readers of putting the discussion into practice.

\section{Case studies}

Based on the concept and procedure of LCC analysis of concrete structures presented in previous sections, four papers are introduced herein, [19], [20], [21], and [22]. The aim of this section is to present applications and case studies written by experts on the advanced technologies for estimating the LCC of structures such as buildings and bridges, considering, in some situations, the risk.

In conjunction with a probabilistic LCC analysis [19] provided a risk-based criterion for optimising repair strategies and various durability design specifications for reinforced concrete structures in marine environments under different exposure conditions. The results of the LCC analysis presented in [19] can be applied to select optimal strategies improving durability of reinforced concrete structures in marine environments.

With budgets coming under increasing constraints and pressure, and demands from service users is not just high but also is increasing, there is an urgent need for a well-considered and validated asset management model to optimize cost and service of council owned building assets. An integrated asset management model to optimize utilization of council's property assets and develop a long-term financial forecast including timely and cost-effective maintenance schedules in order to improve financial planning was proposed in [20].

The impact and interaction of soft story irregularities and construction quality on LCC of reinforced concrete buildings under seismic hazard are investigated in [21]. Results of the analytical works presented in that reference showed that the impact of construction quality was of paramount importance in the overall LCC assessment.

Safi et al. [22] provides insights into various aspects of bridges' LCC and illustrates analytical steps that transportation agencies could apply in bridge procurement. Their study shows that the use of design-build processes, together with the lowest life cycle cost bid as the contract award criterion, afford greater opportunities to consider LCC aspects in bridge procurement, rather than relying on traditional contracts and the lowest-bid criterion.

Introduced approaches to LCC analysis consider all costs incurred over the structure's life-time ranging from initial construction, to maintenance and repair, and to deconstruction. Difference and similarity of LCC estimation between these four papers could be identified depending on their contexts.

\section{Conclusions}

This paper presents in brief the content of a stateof-the-art report concerning LCC analyses for concrete structures prepared by fib Task Group 8.4 on LCC management of concrete structures. The objective is to have the bulletin published by end of 2018. 


\section{References}

[1] Ellingham I. and Fawcett W. (2006), New generation whole-life costing. Property and construction decision making under uncertainty, Taylor \& Francis, UK.

[2] Rackwitz R. (2000) Optimization-the basis of code making and reliability verification. Structural Safety, 22(1), 27-60.

[3] ISO 15686-5, 2008, Buildings and Constructed Assets Service Life Planning Life Cycle Costing, 2008, Geneva, Switzerland.

[4] Linneberg, P, Solgaard, A.O.S, Eriksen, K., Jensen, J.S. (2014). "Challenges within Life Cycle Cost (LCC) Studies and Life Cycle Assessment (LCA)" Proc., IABMAS 2014.

[5] ISO 55000 (2014) Asset management Overview, principles and terminology.

[6] EN 60300-3-3 (2005) Dependability management, Part 3-3: Life cycle costing analysis - Application guide.

[7] EN 15643-4 (2012) Sustainability of Construction Works - Assessment of Buildings - Part 4: Framework for the Assessment of Economic Performance.

[8] ASTM E917-05 (2010) Standard Practice for Measuring Life-Cycle Cost of Buildings and Building Systems.

[9] fib Bulletin 71 (2013) Integrated life cycle assessment of concrete structures, ISBN:978-2-88394-111-3.

[10] FHWA-NJ-2003-012 (2003) Guidelines for Life Cycle Costs Analysis.

[11] FHWA-IF-02-0047 (2002) Life-Cycle Cost Analysis Primer.

[12] SAMPT (2015) Structures Asset Management Planning Toolkit, Atkins.

[13] The Green Book (2011) The Green Book, Appraisal and Evaluation in Central Government, UK Govt, HM Treasury, 2011.

[14] MAINLINE (2013) MAINtenance, renewaL, and Improvement of rail transport iNfrastructure to reduce Economic and environmental impacts, www.mainlineproject.eu.

[15] Journal of Structural Engineering, vol. 142 (9), 2016.

[16] ISO 31000:2009, Risk management Principles and guidelines.

[17] ISO 14040:2006, Environmental management - Life cycle assessment Principles and framework.

[18] ISO 13824:2009, Bases for design of structures - General principles on risk assessment of systems involving structures.

[19] Val, D. V. and Stewart M. G. (2003). "Lifecycle cost analysis of reinforced concrete structures in marine environments." Structural Safety, Vol. 25, pp. 343-362.

[20] Kumar, D., Setunge, S., Patnaikuni, I. (2010). Prediction of life-cycle expenditure for different categories of council buildings. Journal of Performance of Constructed Facilities, 24(6), 556-561.

[21] Tesfamariam, S., Sánchez-silva and Rajeev, P. (2013). "Effect of topology irregularities and construction quality on life-cycle cost of reinforced concrete buildings." Journal of Earthquake Engineering, Vol. 17, pp. 590610.

[22] Safi, M., Sundquist, H. and Karumi, R. (2015). "Cost-efficient procurement of bridge infrastructures by incorporating lifecycle cost analysis with bridge management systems." Journal of Bridge Engineering, 20(6), 04014083-1-12. 